\title{
General Versus Spinal Anesthesia in Laparoscopic Ovarian Cystectomy
}

\author{
Sanam Moradan ${ }^{1, *}$ \\ ${ }^{1}$ Research Center of Abnormal Uterine Bleeding, Semnan University of Medical Sciences, Semnan, IR Iran \\ *Corresponding author: Sanam Moradan, Research Center of Abnormal Uterine Bleeding, Semnan University of Medical Sciences, Semnan, IR Iran. E-mail: sm42595@yahoo.com
}

Received: August 21, 2013; Accepted: December 20, 2013

Background: One of the most common and choice surgical procedures for most elective surgeries are laparoscopy performed preferably under general anesthesia.

Objectives: In this study cases that underwent laparoscopic ovarian cystectomy with general anesthesia were compared with those who were underwent spinal anesthesia.

Patients and Methods: In this prospective analytic study, 60 patients undergone elective laparoscopic ovarian cystectomy received spinal anesthesia or general anesthesia in divided 30 cases.

Results: Duration of surgery was shorter in spinal anesthesia; mean hospital fee was lesser in general anesthesia. Postoperative antiemetic use was higher in spinal anesthesia. Hospital stay time and analgesic use were the same. Conversion to general happened in only one case. Eleven cases experienced shoulder pain during surgery.

Conclusions:Spinal anesthesia was adequate and safe technique in our cases.

Keywords: Anesthesia; Cystectomy; Laparoscopy

\section{Background}

Laparoscopy is one of the most common surgical procedures performed because expertise and instruments have improved [1]. For the anesthetist it is important to understand the advantages and potential risks of method of anesthesia. However general anesthesia is the most common technique, neuroaxial anesthesia has been used in some laparoscopic procedures as the sole technique [2]. Careful choice of the anesthetic technique must be selected to the type of surgery. Peripheral nerve blocks and regional anesthesia are both considered as safe alternative to general for outpatient pelvic laparoscopy [1]. A variety of laparoscopic procedures consists of diagnostic laparoscopy, laparoscopy for infertility and tubal sterilization can be performed under regional anesthesia. The key benefits of regional anesthesia include less emesis, less postoperative pain, shorter postoperative stay, improved patient satisfaction, and overall safety. The physiologic changes during laparoscopy in a wake patient appear to be tolerated well. The benefits of regional anesthesia make it an attractive option to general for many patients and procedures [3]. General anesthesia as the only suitable technique for laparoscopic procedures is a concept of the past. Problems with modern general anesthetics are that these agents do not facilitate postoperative analgesia or an emesis free recovery. There is a growing body of evidence suggesting that regional anesthesia has an important role to play in the care of patients undergoing laparoscopy [3]. In one study on 4,645 cases it was concluded that laparoscopic surgery performed under spinal has several advantages over general anesthesia [4]. Other study was undertaken on 10 patients randomized to receive spinal compared with 10 patients randomized to receive desflurane-based general anesthetic and they concluded that small-dose spinal is an effective alternative to a desflurane general anesthetic in terms of cost and recovery profiles in ambulatory gynecological laparoscopy [5]. Tzovaras et al. study on 100 patients with symptomatic gallstone disease that were randomized to have laparoscopic cholecystectomy under spinal or general anesthesia they concluded that spinal anesthesia is adequate and safe for laparoscopic cholecystectomy in healthy patients and offers better postoperative pain control [6]. Laparoscopic cholecystectomy under spinal anesthesia on 3,492 patients showed that this technique does not require any change and had a number of advantages to general anesthesia, and was introduced as the anesthesia choice [7]. Also using of spinal anesthesia for laparoscopic ventral hernia repair on 23 obese patients proved an efficient and safe alternative to general anesthesia [8].

\section{Objectives}

In this study cases that underwent laparoscopic ovarian cystectomy with general anesthesia were compared with those who were underwent spinal anesthesia.

Copyright (c) 2015, Zahedan University of Medical Sciences. This is an open-access article distributed under the terms of the Creative Commons Attribution-NonCommercial 4.0 International License (http://creativecommons.org/licenses/by-nc/4.0/) which permits copy and redistribute the material just in noncommercial usages, provided the original work is properly cited. 


\section{Patients and Methods}

Prospective analytic studies on 60 women were performed in Amir hospital, Semnan, Iran from May 2011 to April 2012. Written informed consent was obtained and the study was approved by local ethical committee approval. The inclusion criteria was presence of proved simple unilateral ovarian cyst based on pelvic exam and transvaginal ultrasonography, unresponsive to oral contraceptive use at least in previous 2 months duration or cyst size more than $8 \mathrm{~cm}$ in diameter. All these patients that were candidate for elective surgeries divided by simple randomization in two 30 cases in each group. One group received spinal and the other group underwent general anesthesia. Cases that had contraindication for spinal or general anesthesia or any underling diseases were excluded from the study. Induction of spinal anesthesia was done by injection of $10 \mathrm{mg}$ bupivicaine $0.5 \%$ in L3-L4 space with spinal needle $25 \mathrm{~g}$ in sitting position, then the vital signs and $\mathrm{O} 2$ saturation were recorded. Intravenous propofol ( $15 \mu \mathrm{g} / \mathrm{kg} / \mathrm{min})$ were used for patients who developed shoulder or abdominal pain during gas insufflations. Induction of general anesthesia was performed with to use of intravenous. Fentanyl 10-20 $\mu \mathrm{g} /$ $\mathrm{kg}$, thiopental 3-5 $\mathrm{mg} / \mathrm{kg}$ and atrocorium 0.4-0.5 mg/ $\mathrm{kg}$ and maintenance of anesthesia accompanied with isoflurane, fentanyl, atracurium, oxygen and nitrous oxide. Two groups were compared in regard to the time of surgery, time of hospital stay, hospital fee, number of analgesic (intramuscular pentazocine) and number of antiemetic injections (intravenous metoclopramide). Statistical analyses were performed using KolmogorovSmirnov, student t-test, ${ }^{2}$ and Fisher exact tests. SPSS 16 computer software were used and the $\mathrm{P}<0.05$ was considered statistically significant.

\section{Results}

The means for age of the spinal and general groups were $29.7 \pm 7.5$ and $29.6 \pm 8.6$ years respectively so, there was no significant difference between 2 groups. The age sub groups frequency and percentages of the spinal and general groups were $<30$ years old in $13(43.3 \%)$ and 18 (60\%), 30 - 39 years old in $14(46.7 \%)$ and 7 (23.3\%), $\geq 40$ years old in $3(10 \%), 5(16.7 \%)$ respectively. Mean surgical time in spinal group was $51.0 \pm 39$ minute and in general group was $88.3 \pm 45.2$ minutes. Therefore, significant difference was present between 2 groups $(\mathrm{P}=0.001)$. The result of this study showed that the duration of surgery was shorter in spinal group than the general group. Mean hospital fee in spinal and general groups $763338 \pm 2633126$ (Rials) and $2270207 \pm 490072$ (Rials) respectively. There was significant statistical difference between 2 groups $(\mathrm{P}=0.032)$ and the mean hospital fee in spinal group was more than general group. The hospital stay time was less than 8 hours in 29 (96.7\%) cases in spinal and 26 (86.7\%) cases in general group, the differences was not significant. Analgesic was used by 7 (23.30\%) cases in spinal and 9 (30\%) cases in general group. So, no significant difference was present. One (3.3\%) case in spinal and 6 (20\%) cases in general group were used antiemetic and the difference was significant $(\mathrm{P}=0.001)$. Eleven cases in spinal group had bilateral shoulder pain and conversion to general anesthesia was performed in one of them and these results are some disadvantages of spinal anesthesia. None of the cases in spinal group had hypotension or post anesthesia headache (Table 1 ).

\begin{tabular}{|c|c|c|c|}
\hline \multirow[t]{2}{*}{ Variable } & \multicolumn{3}{|c|}{ Study Group } \\
\hline & Spinal & General & P-Value \\
\hline Time of surgery, min & & & 0.001 \\
\hline$<60$ & $20(66.7)$ & $6(20)$ & \\
\hline $60-119$ & $8(26.7)$ & $17(56.7)$ & \\
\hline$\geq 120$ & $2(6.7)$ & $7(23.3)$ & \\
\hline Hospital fee, Rial & & & 0.032 \\
\hline$<2000000$ & $3(10)$ & $10(33.3)$ & \\
\hline $2000000-2999999$ & $21(70)$ & $18(60)$ & \\
\hline$\geq 3000000$ & $6(20)$ & $2(6.7)$ & \\
\hline Hospital stay time, $\mathbf{h}^{\mathrm{b}}$ & $29(96.7)$ & $26(86.7)$ & 0.353 \\
\hline Number of analgesic, dose & $7(23.2)$ & $9(30)$ & 0.559 \\
\hline Number of antiemetic, dose & $1(3.3)$ & $6(20)$ & 0.001 \\
\hline
\end{tabular}

\section{Discussion}

In this study the duration of surgery was shorter and mean hospital fee was lesser in spinal and general anesthesia respectively. There was more antiemetic use in spinal group. In both groups the hospital stay time and analgesic use were the same. Conversion to general anesthesia was performed in only one case, eleven cases experienced shoulder pain during surgery. A retrospective record analysis of 24 patients who received spinal was compared with 28 patients who received general anesthesia. The mean total cost for the spinal group $53.45 \pm 10.40$ USD was no different from that for the general group $48.92 \pm 10.25$ USD. Postoperative antiemetic requirements were similar, whereas analgesic requirements were less in the spinal group (25\%) compared with the general group (75\%) [9]. In this study the mean hospital cost in spinal group was $2633126 \pm 763338$ Rails and in general group was $2270207 \pm 490072$ Rials. The mean hospital cost in spinal group was more than general group. More fees in spinal group may be due to use more devices in this type of anesthesia. One of the benefits of spinal versus general anesthesia in our study was lower incidence of occurrence of emesis after surgery but in regard to dose of the analgesic use both groups were the same. In Ghirardini et al. [10] study spinal anesthesia 
was performed in 60 patients between 21 and 87 years old consists of total abdominal hysterectomies, laparotomic myomectomies, adnexectomies, colposacropexies, and hysterectomies with lymphadenectomy, Burch colposuspension and laparoscopy for sterilization. No significant problems during surgery and the postoperative period were observed. Hospital stay was shorter and compliance was greater than with general anesthesia. In our study none of the cases in spinal group had hypotension or post anesthesia headache and there were no significant differences between spinal and general groups in regard to hospital stay duration [10]. In Sinha et al. [4] study spinal anesthesia was used in 4645 patients. Inject able diclofenac was required in $35.59 \%$ within 2 hours postoperatively, and oral analgesic was required in $63.21 \%$ patients within the first 24 hours. However, $90.02 \%$ of patients under general anesthesia required injectable analgesics in the immediate postoperative period and significant difference was present between two groups [4]. However in our trial analgesic was used by in $23.3 \%$ in spinal group and in $30 \%$ of patients in general group. So, no significant difference was present between two groups. Limitations to the use of spinal anesthesia in laparoscopic surgery are the limited work space, high failure rate, more intra operative morbidity and significant arterial blood gas alterations. Addition of a small-dose ketamine infusion to propofol might provide a suitable sedative combination to be used with high spinal anesthesia [11]. In this study intravenous propofol $(15 \mu \mathrm{g} / \mathrm{kg} / \mathrm{min})$ were used for 11 patients who develop shoulder pain after gas distention during intra abdominal insufflations and in 10 cases pain relieved and continuing of spinal anesthesia were possible. We found propofol as a safe and effective medication in these patients. In a study by Minai et al. awake laparoscopic surgery was performed under spinal anesthesia in 26 years old woman for heterotopic pregnancy. Bilateral shoulder pain occurred with pneumoperitoneum pressure $8 \mathrm{mmHg}$ and pain disappeared after the pneumoperitoneum pressure was decreased to $6 \mathrm{mmHg}$ [12]. Bilateral shoulder pain occurred in 11 cases of spinal group in our study and to use propofol was effective for reliving of pain in 10 of them and conversion to general because shoulder pain was performed in one case. Spinal anesthesia is a safe procedure and new needle have made postdural puncture headache uncommon [13]. There was no case of postdural puncture headache in our study. Yamada et al. reported 7 cases of ovarian cystectomy during pregnancy, using gasless laparoscopic method under combined spinal epidural anesthesia and they concluded that it may be a safe and appropriate technique for laparoscopic ovarian cystectomy [14]. Spinal route of anesthesia in our study also was safe and there were no complications during anesthesia.

\section{Acknowledgements}

This paper is from project number 403 by Dr Sanam Moradan and the author of this paper would like to thank the Dr Aliakbar Hemmati, Anesthesiologist of Amir hospital of Semnan, Iran.

\section{Funding/Support}

Semnan Uninersity of Medical Sciences.

\section{References}

1. Gerges FJ, Kanazi GE, Jabbour-Khoury SI. Anesthesia for laparoscopy: a review. J Clin Anesth. 2006;18(1):67-78.

2. Irwin MG, Wong SSC. Anaesthesia and minimally invasive surgery. Anaesth Intensive Care Med. 2012;13(2):48-51.

3. Collins LM, Vaghadia H. Regional anesthesia for laparoscopy. Anesthesiol Clin North America. 2001;19(1):43-55.

4. Sinha R, Gurwara AK, Gupta SC. Laparoscopic surgery using spinal anesthesia. JSLS. 2008;12(2):133-8.

5. Lennox PH, Chilvers C, Vaghadia H. Selective spinal anesthesia versus desflurane anesthesia in short duration outpatient gynecological laparoscopy: a pharmacoeconomic comparison. Anesth Analg. 2002;94(3):565-8.

6. Tzovaras G, Fafoulakis F, Pratsas K, Georgopoulou S, Stamatiou G, Hatzitheofilou C. Spinal vs general anesthesia for laparoscopic cholecystectomy: interim analysis of a controlled randomized trial. Arch Surg. 2008;143(5):497-501.

7. Sinha R, Gurwara AK, Gupta SC. Laparoscopic cholecystectomy under spinal anesthesia: a study of 3492 patients. J Laparoendosc Adv Surg Tech A. 2009;19(3):323-7.

8. Symeonidis D, Baloyiannis I, Georgopoulou S, Koukoulis G, Athanasiou E, Tzovaras G. Laparoscopic ventral hernia repair in obese patients under spinal anesthesia. Int J Surg. 2013;11(9):926-9.

9. Chilvers CR, Goodwin A, Vaghadia H, Mitchell GW. Selective spinal anesthesia for outpatient laparoscopy. V: pharmacoeconomic comparison vs general anesthesia. Can $J$ Anaesth. 2001;48(3):279-83.

10. Ghirardini G, Baraldi R, Bertellini C, Bertoli C, Bianchini A, Castigliani GP, et al. Advantages of spinal anesthesia in abdominal gynecologic surgery. Clin Exp Obstet Gynecol.1998;25(3):105-6.

11. Ali Y, Elmasry MN, Negmi H, Al Ouffi H, Fahad B, Rahman SA. The feasibility of spinal anesthesia with sedation for laparoscopic general abdominal procedures in moderate risk patients. Middle East J Anaesthesiol. 2008;19(5):1027-39.

12. Minai H, Yamada K, Tashiro K, Yamamoto K. [Anesthetic management for awake laparoscopic surgery for ectopic pregnancy in a patient with heterotopic pregnancy]. persian. Masui. 2005;54(11):1313-4.

13. Hodgson PS, Liu SS. Spinal anesthesia for day surgery. Tech Reg Anesth Pain Manag. 2000;4(1):3-9.

14. Yamada H, Ohki H, Fujimoto K, Okutsu Y. [Laparoscopic ovarian cystectomy with abdominal wall lift during pregnancy under combined spinal-epidural anesthesia]. Masui. 2004;53(10):1155-8. 